\title{
Clinical and electrophysiological appraisal of the significance of radicular injury in back pain ${ }^{1}$
}

\author{
M. A. F ISHER, A. J. SHIVDE, C. TEIXER A, A N D L. S. GR A I N E R \\ From the Departments of Neurological Sciences (Laboratory of Clinical Neurophysiology) and \\ Radio'ogy (Neuroradiology), Rush-Presbyterian-St Luke's Medical Center, Chicago, Illinois, USA
}

SU M M ARY Clinical electrophysiological studies were analysed in 60 consecutive patients with back pain with or without other evidence for a radiculopathy. These studies included needle EMG of relevant limb and paraspinal muscles as well as $F$ responses and $H$ reflexes recorded from the soleus muscle. Segmental denervation was found in 29 of the 60 patients. In 57 patients, abnormal slowing of the $F$ response was present in 27, either unilaterally (25) or bilaterally (two). In 18 of 47 patients with $H$ reflex studies, the $H$ reflex was either unilaterally absent (12), asymmetrically prolonged (five), or bilaterally prolonged (one). Statistically significant $(\mathrm{P}<0.05)$ associations were found between (1) abnormalities of $\mathrm{H}$ reflexes and $\mathrm{F}$ responses, (2) $\mathrm{F}$ response slowing and radicular injury shown by EMG, (3) segmentally consistent radiographic defects and abnormalities of both $\mathrm{H}$ reflexes and $\mathrm{F}$ responses, and (4) depressed Achilles reflexes as well as sensory loss and abnormal $\mathrm{H}$ reflexes. No significant association, however, was present between abnormalities of EMG, $\mathrm{F}$ responses, or $\mathrm{H}$ reflexes and pain radiation by history or positive straight leg-raising tests. These data suggest that pain in radicular syndromes is related to the functioning of smaller afferent fibres.

The specific nature of the significant injury (or injuries) in patients with back pain has not been defined. In the discussion after Mixter and Barr's (1934) classic presentation of the syndrome of the herniated intravertebral disc, Dr Mixter stated that he did not know "why these patients have tenderness along the sciatic nerve." Unfortunately, our understanding of the relation between radicular injury and its clinical presentation is no better today than in 1934.

For this reason a series of electrodiagnostic studies on patients with back pain was analysed. These studies provided physiological evidence of radicular injury by abnormalities on needle electromyography of muscles (EMG) as well as by studies reflecting proximal conduction in nerves, namely

\footnotetext{
${ }^{1}$ Presented in part at the IXth International Congress of Electroencephalography and Clinical Neurophysiology, Amsterdam, September 1977.

Address for reprint requests: Dr M. A. Fisher, Department of Neurological Sciences, EMG Laboratory, Rush-Presbyterian-St Luke's Medical Center, 1753 West Congress Parkway, Chicago, Illinois 60612, USA.

Accepted 31 October 1977
}

$\mathrm{H}$ reflexes and $\mathrm{F}$ responses. From this we hoped to obtain more specific information as to the significant physiological injury in these patients.

\section{Patients and methods}

Data from 60 consecutive patients with a chief complaint of back pain referred to the Electromyography (EMG) Laboratory at PresbyterianSt Luke's Hospital were analysed. These patients may or may not have had other evidence for a radiculopathy, but in none of the patients was there evidence to suggest other central or peripheral nervous system dysfunction. The patients ranged in age from 18 to 75 years with an average age of 44 years.

Needle electromyographic examination was performed on at least the following muscles on at least one side: tibialis anterior, medial gastrocnemius-soleus, peronei, rectus femoris, and the paraspinal muscles at two or more lumbar or sacral myotome levels. All muscles were tested by a minimum of one four quadrant examination with at least three samplings in each quadrant-that is, 
12 different locations. In muscles considered abnormal, fibrillations or positive sharp waves or both, were found in two or more areas.

When recording $\mathbf{H}$ reflexes, the distance was measured between the stimulation point of the tibial nerve in the region of the midpopliteal crease and the most proximal part of the medial malleolus following the course of the nerve. The active recording site was on the medial aspect of the soleus muscle half the distance between these points. The indifferent electrode was placed at least $50 \mathrm{~mm}$ distally on the muscle belly.

The $F$ responses were recorded in a similar way except that the stimulus, rather than being submaximal, was approximately $25 \%$ supramaximal. As the $\mathrm{H}$ reflexes and $\mathrm{F}$ responses were recorded from the same sites, the distinction between these two responses could be made with relative ease. Criteria for this distinction have been published (Shahani and Young, 1976). Latencies of $F$ responses were calculated from the average of 10 responses (Shivde et al., 1977).

Normal values for $\mathrm{H}$ reflex latencies as well as significant latency differences between sides (that is, $2 \mathrm{~ms}$ or greater) were based on Braddom and Johnson's (1974) work and confirmed in our own laboratory. Comparable data for average $\mathbf{F}$ latencies were obtained from 23 control subjects as well as from the 60 patients studied. An average $F$ response latency difference of greater than $2 \mathrm{~ms}$ between sides was considered abnormal.

All patients were examined by one of the authors. The straight leg-raising test was performed by flexing the extended leg at the hip. It was considered positive if discomfort was felt in at least the lumbosacral region or posterior aspect of the thigh with the hip flexed at less than $60^{\circ}$ to the horizontal. Twenty-two of the 60 patients had myelograms, and 21 of these were available for study by one of the authors (LSG). At the time of this review, only four of the 60 patients had undergone surgery. Surface limb temperature was monitored and maintained at greater than $32^{\circ}$. Statistical analysis was performed by standard methods - the $\chi^{2}$ test or, if the expected counts were too small, Fisher's exact test.

\section{Results}

F responses were obtained bilaterally in 57 of the 60 patients. In 27 of these patients, $F$ responses were abnormal in that there was either bilateral prolongation of the average $F$ response latency (two) or the latency was more than $2 \mathrm{~ms}$ on one side in comparison to the other studies (25). If there were asymmetrical clinical signs and/or symptoms, the longer latency was always on a clinically involved side.

$\mathrm{H}$ reflexes were obtained in 47 patients. In 18, the studies were abnormal. In five of these patients, the $\mathrm{H}$ reflex latency on a clinically involved side was greater than on a clinically uninvolved side by $2 \mathrm{~ms}$ or more, while in 12 studies the $\mathrm{H}$ reflex was absent in a clinically involved limb. In one patient, $\mathrm{H}$ reflex latencies bilaterally were close to two standard deviation units higher than normal for age. All other $\mathrm{H}$ reflex latencies were within one standard deviation unit for age.

Evidence of denervation on needle examination of muscles was present in 29 of the 60 patients. Eight of these studies showed injury to either the L5 root alone or to the L4 and L5 roots; in 21 patients, there was injury to at least the $S 1$ root. In four patients, this was based on abnormalities in the paraspinal muscles alone; in 13, on evidence of denervation in an involved limb alone; and in 12 , on evidence of abnormalities in both limb and paraspinal muscles.

Table 1 shows the correlation of the EMG, $F$ 망 response, and $\mathrm{H}$ reflex studies with each other as well as with pain radiation, positive straight legraising tests, absent (18) or decreased (two) Achilles reflexes, and sensory loss. The sensory loss involved at least decreased sensation to touch and pin on the lateral or plantar or both aspects of the foot on a clinically involved side.

There is a strong correlation $(P<0.001)$ between abnormalities of the Achilles reflex and abnormalities of the $\mathrm{H}$ reflex. All 12 patients with absent $H$ reflexes had absent (11) or decreased (one) Achilles reflexes. There is also a significant $(P<0.05)$ association between sensory loss and abnormalities of the $\mathrm{H}$ reflex (absent in seven, asymmetrically prolonged in two).

Prolonged $\mathrm{F}$ responses correlated with abnormal $H$ reflexes $(P<0.01)$ as well as abnormal findings on needle EMG examination $(P<0.05)$. Closer examination (Table 2) reveals that there is a correlation $(P<0.02)$ between abnormal $F$ responses and evidence of injury at the S1 root level on EMG examination.

In the 21 patients with myelograms available for review, 16 had abnormal EMGs. In 15 of these, the level of injury defined by electromyography was clearly consistent with the radiographic defects. In one patient, myelographic abnormalities were seen only at the L5-S1 level while the patient was thought to have evidence of L4-5 root injury on EMG. Table 3 shows that there was a statistically significant association $(P<0.05)$ between radiographic defects at the L5-S1 level (in com- 
Table 1 EMG, $F$ response, and $H$ reflex related to clinical symptoms and signs

\begin{tabular}{|c|c|c|c|c|c|c|}
\hline & \multicolumn{2}{|l|}{$E M G$} & \multicolumn{2}{|c|}{ F response } & \multicolumn{2}{|l|}{$H$ reflex } \\
\hline & Normal & Abnormal & Normal & Abnormal & Normal & Abnormal \\
\hline Total number & 31 & 29 & 30 & 27 & 29 & 18 \\
\hline Pain & 21 & 23 & 19 & 23 & 22 & 11 \\
\hline Positive straight leg-raising test & 21 & 17 & 15 & 22 & 15 & 13 \\
\hline Absent or decreased Achilles reflex & 8 & 12 & 7 & 12 & $1 \ddagger$ & $12 \ddagger$ \\
\hline Sensory loss & 6 & 7 & 7 & 5 & $4 \S$ & $9 \S$ \\
\hline F normal & 20 & 10 & - & - & 17 & $2 \dagger$ \\
\hline abnormal & 9* & $18^{*}$ & - & - & 10 & $15 \dagger$ \\
\hline H normal & 15 & 14 & 17 & 10 & - & - \\
\hline abnormal & 10 & 8 & $2 \dagger$ & $15+$ & - & - \\
\hline
\end{tabular}

${ }^{*} \mathrm{P}<0.05 ;+\mathrm{P}<0.01 ; \ddagger \mathrm{P}<0.001 ; \S \mathrm{P}<0.05$.

Table $2 F$ response, $H$ reflex, and $E M G$

\begin{tabular}{llllll}
\hline $\begin{array}{l}\text { Radicular } \\
\text { injury }(E M G)\end{array}$ & \multicolumn{2}{l}{ Fresponse } & & \multicolumn{2}{l}{ H reflex } \\
\cline { 2 - 3 } \cline { 5 - 6 } \cline { 5 - 6 } & Normal & Abnormal & & Normal & Abnormal \\
\hline L4-5 or L5 & 6 & 2 & 5 & 1 \\
L5-S1 or S1 & 4 & 17 & 9 & 7 \\
& & $P<0.02$ & & \\
\hline
\end{tabular}

Table 3 F response, $H$ reflex, and myelography

\begin{tabular}{|c|c|c|c|c|}
\hline \multirow{2}{*}{$\begin{array}{l}\text { Myelographic } \\
\text { defects }\end{array}$} & \multicolumn{2}{|c|}{ F response } & \multicolumn{2}{|l|}{$H$ reflex } \\
\hline & Normal & Abnormal & Normal & Abnormal \\
\hline $\begin{array}{l}\text { L4-5 alone } \\
\text { L5-S1 }\end{array}$ & $\begin{array}{l}6 \\
2\end{array}$ & $\begin{array}{c}3 \\
10 \\
0.05\end{array}$ & $\begin{array}{l}7 \\
6\end{array}$ & $\begin{array}{c}0 \\
5 \\
0.05\end{array}$ \\
\hline
\end{tabular}

parison to the L4-5 level alone) and abnormalities of $F$ responses and $H$ reflexes.

At the same time (Table 1) there was no statistically significant correlation with pain radiation and positive straight leg-raising with either abnormalities of EMG, $F$ responses, or $H$ reflexes, nor was there any significant correlation with depressed Achilles reflexes or sensory loss with EMG or F response abnormalities. Table 4 shows that this lack of association between pain radiation or positive straight leg-raising tests and abnormal $F$ responses or $H$ reflexes is true even if one analyses the data only from those patients with EMG evidence of S1 root injury.

Only six patients in this series had clear motor weakness. This was characterised by at least weak-

Table 4 S1 radicular injury $(E M G)$

\begin{tabular}{llllll}
\hline & \multicolumn{2}{l}{ Fresponse } & & H reflex \\
\cline { 2 - 3 } \cline { 5 - 6 } \cline { 5 - 6 } & Normal & Abnormal & & Normal & Abnormal \\
\hline Total number & 4 & 17 & 9 & 7 \\
Pain radiation & 3 & 13 & 7 & 5 \\
$\begin{array}{l}\text { Positive straight } \\
\text { leg-raising }\end{array}$ & 2 & 13 & 5 & 6 \\
\hline
\end{tabular}

ness of dorsiflexion of the large toe. In five of these patients, there was EMG evidence of denervation involving the L5 root.

\section{Discussion}

This study demonstrates that physiological evidence of radicular injury is not necessarily associated with common "radicular" signs and symptoms.

In this series of 60 patients referred for evaluation of back pain, some electrodiagnostic abnormalities were demonstrated in 43-abnormal $F$ responses alone in six, abnormal $\mathrm{H}$ reflexes alone in five, abnormal $H$ reflexes and $F$ responses in three, and at least EMG abnormalities in 29. This high percentage of abnormal findings almost certainly reflects the selected nature of the population studied. The patients were seen by physicians at a major medical centre, and then only those patients of concern were referred for electrodiagnostic evaluation.

The data are consistent with the measurement of meaningful physiological changes. Abnormalities of both $H$ reflexes and $F$ responses recorded from the soleus muscle correlated with structural abnormalities which would be expected to involve the $\mathrm{S} 1$ root. There is also a statistically significant association between abnormalities of both $\mathrm{H}$ reflexes and $F$ responses indicating injury at a common level. At the same time, there is an association between depressed Achilles reflexes (as well as segmentally consistent sensory loss) and abnormal $H$ reflexes. This is consistent with the $H$ reflex being the electrical equivalent of the deep tendon reflex (Magladery et al., 1951). Similarly, the $F$ response is thought to reflect antidromic activation of motoneurones. The $F$ response is present in the absence of afferent input in both animals and man (Gassel and Wiesandanger, 1965; McLeod and Wray, 1966; Mayer and Feldman, 1967; Miglietta, 1973). It is not surprising that 
there should be a correlation between abnormalities of the $F$ response (in contrast to the $H$ reflex) and injury to the ventral root as manifested by evidence of segmentally consistent denervation on needle EMG examination.

It was, therefore, striking to find that there was no significant correlation of abnormalities of EMG, $F$ responses, or $H$ reflexes, with a history of pain radiation or abnormal straight leg-raising tests. As a history of pain radiation may have little localising value (Barr, 1937; Knuttson, 1961), it may be that tests dependent on local radicular injury would not be so specific. A positive straight leg-raising test, however, has been considered of "decisive importance" for the clinical diagnosis of lumbar disc herniation (Knuttson, 1961).

The data from this study would, therefore, indicate that common painful features of radicular injury cannot be related simply to axonal damage of the ventral roots fibres as manifested by denervation nor to damage to the larger afferent fibres as shown by $\mathrm{H}$ reflex changes. This would also be true for demyelination of efferent fibres (or, less likely, selective damage to the largest of these fibres) as shown by slowing of the $F$ response.

It is possible that much of the pain in radicular syndromes is related to injury or abnormal stimulation of the smaller afferent fibres such as $C$ fibres. Afferent impulses in these fibres are at least a "necessary and sufficient" condition for eliciting pain under certain circumstances (Mountcastle, 1974), and damage to these small unmyelinated fibres would not be shown by the clinical physiological tests discussed in this paper. It is conceivable that significant improvement in our treatment of back pain will depend on a better understanding of the unique characteristics of these fibres. At the least, we feel that awareness of the complexity of association between radicular injury and the disabling pain experienced in syndromes such as a herniated disc can only be helpful.

The technical assistance of Ms Barbara Karakusis is acknowledged gratefully.

\section{References}

Barr, J. S. (1937). "Sciatica" caused by intervertebral disc lesion. Journal of Bone and Joint Surgery, 19, 323-342.

Braddom, R. I., and Johnson, E. W. (1974). Standardization of $\mathbf{H}$ reflex and diagnostic use in $\mathbf{S 1}$ radiculopathy. Archives of Physical Medicine and Rehabilitation, 55, 161-166.

Gassell, M. M., and Wiesandanger, M. (1965). Recurrent and reflex discharges in plantar muscles of the cat. Acta Physiologica Scandinavica, 66, 138142.

Knuttson, B. (1961). Comparative value of electromyographic, myelographic, and clinical neurological examination in diagnosis of lumbar root compression syndrome. Acta Orthopaedica Scandinavica, Supplement 49, 1-135.

McLeod, J. G., and Wray, S. H. (1966). An experimental study of the $F$ wave in the baboon. Journal of Neurology, Neurosurgery, and Psychiatry, 29, 196-200.

Magladery, J. W., Porter, W. E., Park, A. M., and Teasdall, R. D. (1951). Electrophysiological studies of nerve and reflex activity in normal man. IV. The two neurone reflex and identification of certain action potentials from spinal roots and cord. Bulletin of the Johns Hopkins Hospital, 88, 499519.

Mayer, R. F., and Feldman, R. G. (1967). Observation on the nature of the $\mathrm{F}$ wave in man. Neurology (Minneapolis), 17, 147-156.

Miglietta, O. E. (1973). The response after transverse myelotomy. In New Developments in Electromyography and Clinical Neurophysiology, Vol. 3, pp. 323-327. Edited by J. E. Desmedt. Karger: Basel.

Mixter, W. J., and Barr, J. S. (1934). Rupture of the intervertebral disc with involvement of the spinal canal. New England Journal of Medicine, 211, 210 215.

Mountcastle, V. B. (1974). Pain and temperature sensibilities. In Medical Physiology, Vol. 1, pp. 348-381. Edited by V. B. Mountcastle. C. V. Mosby: St Louis.

Shahani, B. T., and Young, R. R. (1976). Effect of vibration on the $\mathrm{F}$ response. In The Motor system: Neurophysiology and Muscle Mechanisms, pp. 189195. Edited by M. Shahani. Elsevier: Amsterdam.

Shivde, A. J., Teixera, C., and Fisher, M. A. (1977). The $F$ response-a clinically useful physiological parameter for the evaluation of back pain. Twentyfourth Annual Meeting of the American Association of Electromyography and Electrodiagnosis. Salt Lake City, Utah, 30 September-1 October 1977. 